British Journal of Applied Physics

Edited by Dr. H. R. Lang. Vol. 5, 1954, and Supplement No. 3: The Physics of Particle Size Analysis - a Conference arranged by the Institute of Physies and held in the University of Nottingham from the 6 to 9 April, 1954. Pp. vi $+466+$ supplement 218. (London: Institute of Physics, 1954.) £5 14s. $6 d$.

TN its annual report to the board of the Institute 1 of Physies, the advisory committee of the British Journal of Applied Physics recently commented on the satisfactory increased circulation and high standard of the Journal, and this is amply justified by Vol. 5 which covers 1954 . The volume contains twelve special articles, three conference reports and seventy-nine original contributions, in addition to a lengthy supplement of 218 pages.

Most of the special articles consist of lectures delivered by their authors to various branch and group meetings of the Institute. R. W. G. Wyckoff writes on the growth of X-ray diffraction work in the United States- the subject of his evening discourse to the.X-ray Analysis Group on November 20, 1953 ; W. A. Wooster on diffuse X-ray scattering and the physical properties of crystals; $O$. R. Frisch on the beginnings of atomic energy, and $R$. Fürth on statistical concepts in theoretical physics, both lectures to the Education Group; V. Daniel on the thermodynamic approach to solid structure; and others on such varied topics as supersonic gas flow, the electrical breakdown of gases, the junction transistor, and the near infra-red absorption spectra of fibres. In the three conference reports, the proceedings are summarized of the conferences on X-ray analysis held in London during November 1953 and in Cambridge during April 1954, and on electron microscopy in London during November 1953.

The secretary of the Institute of Physics and editor of the Institute's journals, Dr. H. R. Lang, contributes the editorial note to the supplement, which is a record of the proceedings of the conference on the physics of the analysis of particle size, arranged by the Institute and held at the University of Nottingham during April 6--9, 1954 . Forty-two papers were presented, and these, together with the discussions on them, are grouped in eight sections corresponding to the eight sessions into which the conference was divided. It is sufficient recommendation to quote from Sir Geoffrey Taylor's opening remarks that new and valuable contributions to the scientific study of the processes of particle separation are to be found in all the papers presented to the conference.

\section{Geology in Engineering}

By Dr. John R. Schultz and Dr. Arthur B. Cleaves. With a Chapter on Soil Mechanics by E. J. Yoder. Pp. ix +592 . (New York: John Wiley and Sons, Inc.; London: Chapman and Hall, Ltd., 1955.) $70 s$. net.

THIs well-planned and well-written book deals with the application of geology to civil engineering. It is more than a text-book of geology for engineers, since it discusses geology in such a way that engineers, on one hand, can appreciate when and to what extent they may expect the geologist to help them, and the geologist, on the other, may appreciate the problems with which the engineer has to deal.

The book is concerned with principles rather than case-histories, because it is the authors' opinion that the engineer will employ the geologist more for the inferences he will make than for his factual knowledge. Attention is directed to the necessity for the geologist to know what the engineer is aiming at in order that he may give the right information in the most useful form, while the engineer, on his part, must be able to appreciate the significance of what the geologist tells him.

The book is divided into twenty-two chapters, of which two-thirds deal with those geological processes and phenomena that have special application in engineering projects and difficulties, and the remainder with specific topics such as dams, reservoirs, roads and tunnels, and with recent developments in the field of soil mechanics and the uses of aerial photography in interpreting soil distribution and recognizing geological structures.

The reproduction of the half-tone illustrations which are distributed through the text leaves much to be desired; but there are many excellent textfigures, a useful bibliography at the end of each chapter, and an adequate index. F. J. North

The Golden Eagle

King of Birds. By Seton Gordon. Pp. ix $+246+$ 16 plates. (London : William Collins, Sons and Co., Ltd., 1955.) 16s. net.

R. SETON GORDON has lived all his life in 11 the Scottish Highlands, has had exceptional opportunities of watching eagles, and has made good use of them. Not only has he kept nests under daily observation from the laying of eggs to first flight of the young, but he has also watched the adults hunting in mid-winter when the hills are covered with snow, and later seen them pair and build the nest. The results of all these observations are presented in a very readable form and include a number of new facts. No attempt is made to estimate the number of breeding pairs of golden eagles; but it may be said that during the past twenty-five years the numbers have been more or less stationary-a decrease in one part of the country and an increase in another. It is interesting to learn that birds have returned to their old haunts in the wilds of Galloway and Carrick and northern Ireland. A chapter is devoted to the use of the eagle in falconry, and we learn that in central Asia birds are used for hunting wolves, foxes and gazelle.

With the advent of sheep farming, and grouse shooting becoming a source of income to Highland lairds, the eagle would have been doomed if it were not for the enlightened policy of some landowners. That the eagle does take lambs at times there is ample evidence, and Mr. Seton Gordon himself has seen one carrying off a lamb. Nevertheless, he considers that "In Scotland the number of lamb-killing eagles is small-less than five percent". He goes on to say that lambs are not a regular prey of eagles in Scotland any more than man is of a tiger. Blue hares and rabbits are the prineipal food, and one wonders what they will turn to now that the latter have become so scarce.

The eagle's prey is varied and includes various mammals, grouse, geese and other birds. Though $a$ number of grouse are taken, the author does not think they are destroyed in sufficient numbers to affect the stock on a moor; on the other hand, eagles kill grey crows, and it would be interesting to know whether the crow or the eagle has the greatest effect on the grouse population. A number of beautiful photographs adds much to the value of this interesting book.
N. KINNEAR 